\title{
A Simulation Based Performance Comparison of AODV and DSDV Mobile Ad Hoc Networks
}

\author{
Subhrananda Goswami \\ Department of Computer Science, Haldia Institute of Technology, Haldia, Purba Midnapore, West Bengal, India \\ Email: subhrananda_usca@yahoo.co.in \\ Subhankar Joardar \\ Department of Computer Science, Haldia Institute of Technology, Haldia, Purba Midnapore, West Bengal, India \\ Email: subhankarranchi@yahoo.co.in
}

Chandan Bikash Das

Department of Mathematics,Tamralipta Mahavidyalaya, Tamluk, Purba Midnapore-721636, India

Email: cdas_bikash@yahoo.co.in

\section{Barun Das}

Department of Mathematics, Sidho-Kanho-Birsa University, Purulia-723101, India

Email: barundas2004@yahoo.co.in

\begin{abstract}
Mobile Ad hoc Network (MANET) is formed by a group of autonomous mobile nodes connected by wireless links, in which there is no backbone infrastructure. In this work, an attempt has been made to understand the characteristics/behavior of Ad hoc On Demand Distance Vector (AODV) and Destination Sequence Distance Vector (DSDV) routing protocols when operating in more challenging environment such as frequent change in network topology and node density. The performance differentials are analyzed using throughput, Packet Delivery Ratio and normalized routing load which shall provide an insight about the sensitivity of the protocols under consideration when exposed in more challenging environment. Simulation based analysis of the protocols have been done using NS-2.
\end{abstract}

Index Terms - AODV, DSDV, MANET, Throughput, Packet Delivery Ratio and Normalized Routing Overhead, NS2

\section{INTRODUCTION}

Tenenbaum[1] defines computer networks as a system for communication between computers. These networks may be fixed (cabled, permanent) or temporary. A network can be characterized as wired or wireless. Wireless can be distinguished from wired as no physical connectivity between nodes are needed. Mobile Ad-Hoc network is a kind of wireless network and self configuring network of moving routers associated with wireless network. The routers are free to move randomly and organize themselves arbitrarily, thus, the network's wireless topology may change rapidly and unpredictably. [2][3] Mobile Ad-Hoc network is an infractureless network due to mobile routers. Each node or router must forward the packets unrelated to its own use. [4][5][6] Main challenges to maintain the Mobile Ad-Hoc network are: No central controlling authority, limited power ability, continuously maintain the information required to properly route traffic.

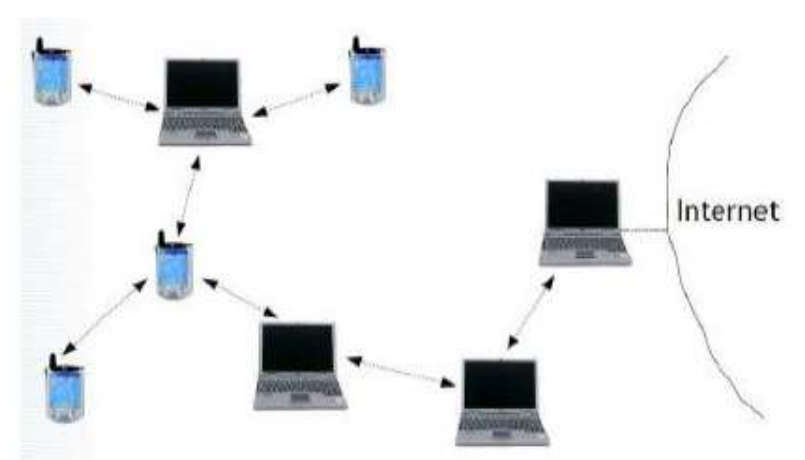

Fig. 1. Mobile Ad-hoc Network

Figure 1 illustrates the working of a MANET containing mobile nodes. The nodes configure themselves and establish a connection with the other nodes that are within their range of communication. Each mobile node in the MANET is independent and can move in any direction, thus, the links to other nodes in the network keep changing constantly. Each node must behave as an intermediate node by forwarding traffic that is not related to it, hence, performing the duties of a router. This is the main challenge in the configuration of a MANET to configure each node to behave as a router. Such networks once configured can operate independently or can be connected to the Internet.

MANETs do not use any form of fixed infrastructure or centralised administration. These types of networks have the following salient characteristics: dynamic topologies, bandwidth-constrained variable capacity links, limited physical security and energy constrained operations. Various dedicated routing protocols have been proposed to the Internet Engineering Task Force (IETF) MANET Working Group [7]. Some of these protocols have been studied and their performances have been analysed in detail. J. Broch et al [8] evaluated four 
protocols using mobility and traffic scenarios similar to those we used. They focused on packet loss, routing message overhead and route length. In [9], P. Johansson et al, compare three routing protocols, over extensive scenarios, varying node mobility and traffic load. They focus on packet loss, routing overhead, throughput and delay, and introduce mobility measures in terms of node relative speed. Finally, in [10] S. R. Das et al, compare the performance of two protocols, focussing on packet loss, packet end to end delay and routing load. They obtained simulation results consistent with previous works and conclude' with some recommendations for improving protocols.

In this work, we measure and compare three performance parameter behaviour of two routing protocols; respectively Ad-hoc On Demand Distance Vector(AODV)[11] and Destination-Sequenced Distance Vector (DSDV). Destination-Sequenced Distance Vector (DSDV) routing protocol is a typical routing protocol for MANETs, which is based on the Distributed BellmanFord algorithm [12].

This paper is organized with nine section. Section I represent brief introduction. Section II represents problems with routing in MANETs. Section III classifies some routing protocols. Section IV represents details of AODV protocols. The DSDV routing protocols is described in sectionV. The distinguishes between reactive and proactive protocols is presented in section VI. In section VII, we represent network simulator and performance metric. The graphical analysis of performance parameter is done in section VIII. The conclusion is given in section IX. At the end of this paper give acknowledgement, list of reference of work and little bit introduction of us.

\section{PROBLEMS WITH ROUTING IN MOBILE AD-HOC NETWORKS}

- Asymmetric links: Most of the wired networks rely on the symmetric links which are always fixed. But this is not a case with ad-hoc networks as the nodes are mobile and constantly changing their position within network. For example consider a MANET where node B sends a signal to node A but this does not tell anything about the quality of the connection in the reverse direction .

- Dynamic Topology: This is also the major problem with ad-hoc routing since the topology is not constant. The mobile node might move or medium characteristics might change. In ad-hoc networks, routing tables must somehow reject these changes in topology and routing algorithms have to be adapted. For example in a fixed network routing table updating takes place for every $30 \mathrm{sec}$. This updating frequency might be very low for ad-hoc networks.

- Routing Overhead: In wireless ad-hoc networks, nodes often change their location within network. So, some stale routes are generated in the routing table which leads to unnecessary routing overhead.

- Interference: This is the major problem with mobile ad-hoc networks as links come and go depending on the transmission characteristics, one transmission might interfere with another one and node might overhear transmissions of other nodes and can corrupt the total transmission.

\section{Routing PROTOCOLS}

The existing routing protocols in MANETs can be classified into three categories. Figure 2 shows the classification along with some examples of existing MANET protocols.

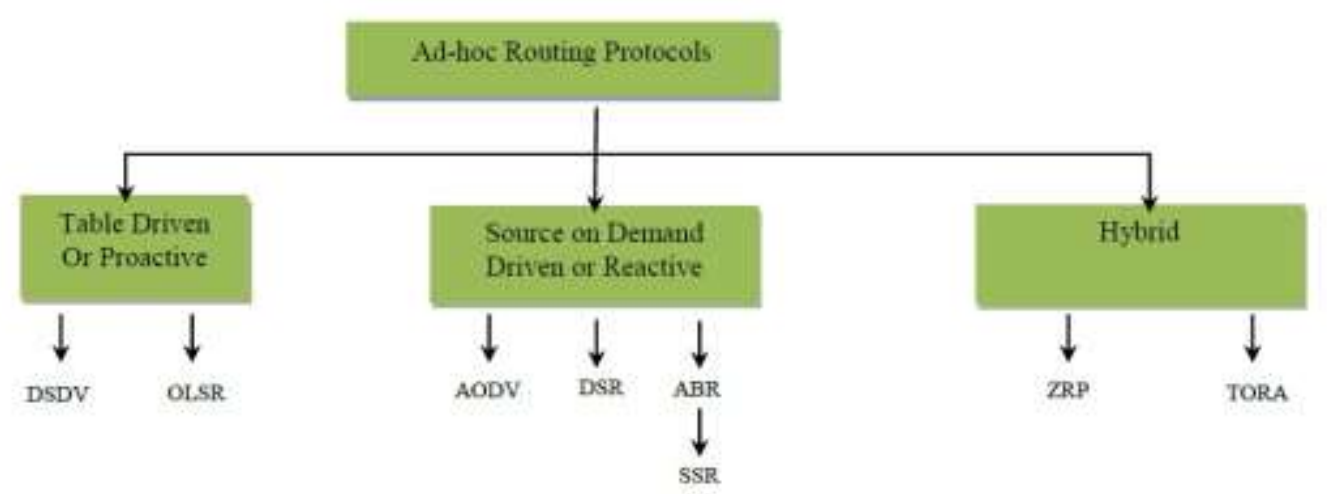

Fig. 2. Classification of MANETs Routing Protocols

\section{AD-HOC ON-DEMAND DistANCE VECTOR(AODV)}

AODV is a very simple, efficient, and effective routing protocol for Mobile Ad-hoc Networks which do not have fixed topology. This algorithm was motivated by the limited bandwidth that is available in the media that are used for wireless communications. AODV is a reactive protocol, even though it still uses characteristics of a proactive protocol [10]. AODV takes the interesting parts of DSR and DSDV in the sense that it uses the concept of route discovery and route maintenance of DSR and the concept of sequence numbers and sending of periodic hello messages from DSDV.

The protocol uses different messages to discover and maintain links: 
- Route Requests(RREQ): A node disseminates a RREQ when it determines that it needs a route to a destination and does not have one available. This can happen if the destination is previously unknown to the node, or if a previously valid route to the destination expires or is marked as invalid. The Destination Sequence Number field in the RREQ message is the last known destination sequence number for this destination and is copied from the Destination Sequence Number field in the routing table. Before broadcasting the RREQ, the originating node buffers the RREQ ID and the Originator IP address (its own address) of the RREQ for PATH_DISCOVERY_TIME. In this way, when the node receives the packet again from its neighbours, it will not reprocess and reforward the packet[10].

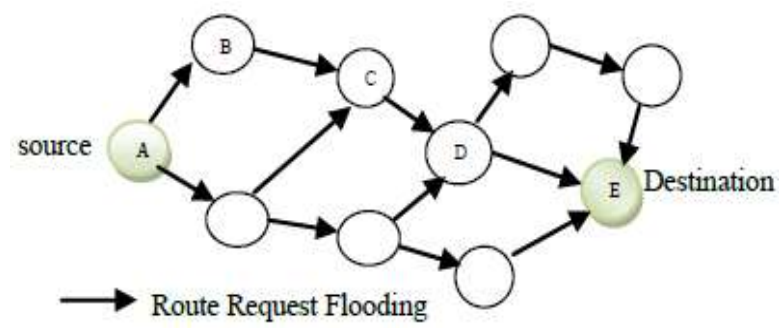

Fig. 3. Propagation of Route Request (RREQ) Packet

- Route Replies(RREP): A node generates a RREP if either[10]:

(i) It is itself the estimation, or

(ii) It has an active route to the destination, the destination sequence number in the node's existing route table entry for the destination is valid and greater than or equal to the Destination Sequence Number of the RREQ (comparison using signed 32-bit arithmetic), and the "destination only" ('D') flag is NOT set.

When generating a RREP Message, a node copies the Destination IP Address and the Originator Sequence Number from the RREQ message into the corresponding fields in the RREP message.

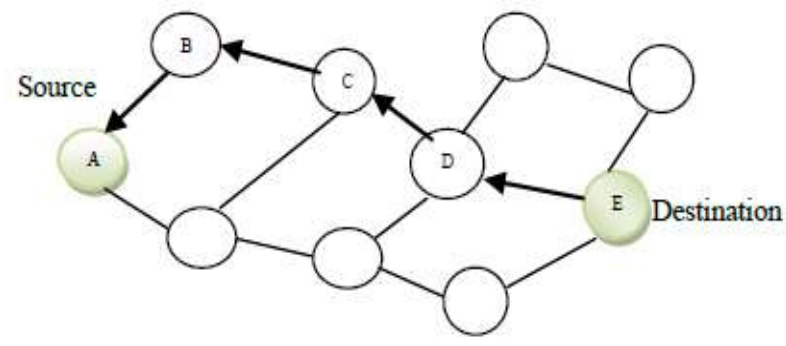

\section{$\longleftarrow$ Route Reply Propagation}

Fig. 4. Propagation of Route Reply(RREP) Packet

- Route Error message: The neighbourhood nodes are monitored. When a route that is active is vanished, the neighbourhood nodes are notified by RERR (Route Error Message) on both sides of link[10].

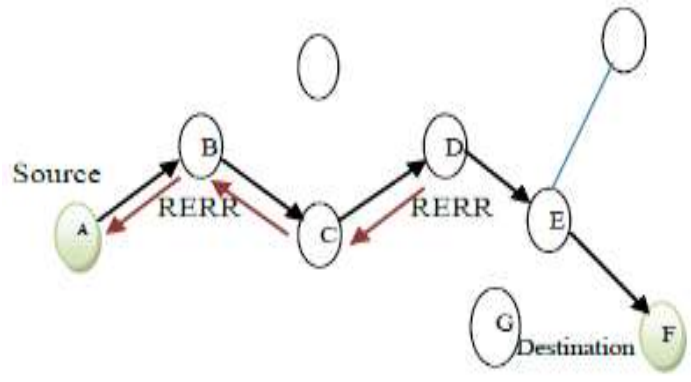

Fig. 5. Route Error (RERR) Packet

A node initiates processing for a RERR message in three situations:

(i) If it detects a link break for the next hop of an active route in its routing table while transmitting data (and route repair, if attempted, was unsuccessful), or

(ii) If it gets a data packet destined to a node for which it does not have an active route and is not repairing (if using local repair), or

(iii)If it receives a RERR from a neighbour for one or more active routes.

- Hello Messages: A node MAY offer connectivity information by broadcasting local Hello messages. A node SHOULD only use hello messages if it is part of an active route. Every HELLO_INTERVAL milliseconds, the node checks whether it has sent a broadcast (e.g., a RREQ or an appropriate layer 2 message) within the last HELLO_INTERVAL.

\section{A. Interesting concepts of AODV}

The concepts of AODV that make it desirable for MANETs with limited bandwidth include the following:

- Minimal space complexity: The algorithm makes sure that the nodes that are not in the active path do not maintain information about this route. After a node receives the RREQ and sets a reverse path in its routing table and propagates the RREQ to its neighbours, if it does not receive any RREP from its neighbours for this request, it deletes the routing info that it has recorded.

- Maximum utilization of the bandwidth: This can be considered the major achievement of the algorithm. As the protocol does not require periodic global advertisements, the demand on the available bandwidth is less.

- Simple: It is simple with each node behaving as a router, maintaining a simple routing table, and the source node initiating path discovery request, making the network self starting.

- Most effective routing info: After propagating an RREP, if a node finds receives an RREP with smaller hop-count, it updates its routing info with this better path and propagates it.

\section{DestinAtion SEQUENCED DistANCE VeCtoR (DSDV)}

The destination sequenced distance vector (DSDV) routing protocol is a proactive routing protocol which is a 
modification of conventional Bellman-Ford routing algorithm. This protocol adds a new attribute, sequence number, to each route table entry at each node. Routing table is maintained at each node and with this table, node transmits the packets to other nodes in the network. This protocol was motivated for the use of data exchange along changing and arbitrary paths of interconnection which may not be close to any base station.

The broadcasting of the information in the DSDV protocol is of two types namely: full dump and incremental dump. Full dump broadcasting will carry all the routing information while the incremental dump will carry only information that has changed since last full dump. Irrespective of the two types, broadcasting is done in network protocol data units (NPDU). Full dump requires multiple NPDUs while incremental requires only one NPDU to fit in all the information.

Consider the above figure 6 which has 8 hosts in the network. We will have a look at the changes to the MH4 routing table with reference to the movements of MH1. Initially, all the nodes advertise their routing information to all the nodes in the network.

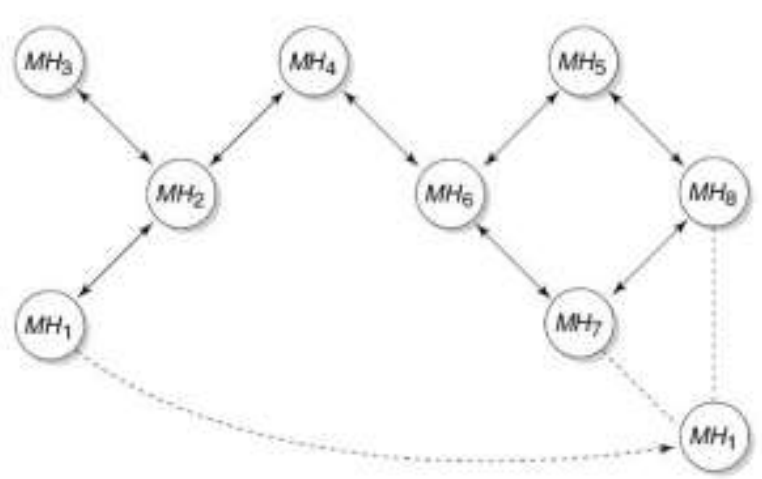

Fig. 6. Movement of Mobile host in Adhoc Networks

\section{Contrast ReActive AND PROACTIVE Protocols}

The simulations method is available with AODV and DSDV protocols. The outputs only depend with different regulations. The following table shows the aspects between AODV and DSDV.

Table 1. Proactive vs reactive protocol

\begin{tabular}{|l|l|}
\hline \multicolumn{1}{|c|}{ Proactive Protocols } & Reactive Protocols \\
\hline $\begin{array}{l}\text { Every time it will update routing table in the nodes. } \\
\text { All the nodes are changing their position often. }\end{array}$ & $\begin{array}{l}\text { Reactive protocols not update the routing information } \\
\text { as like reactive it will update the information only if it is needed. }\end{array}$ \\
\hline $\begin{array}{l}\text { There is no topology occurs periodically, } \\
\text { then the constant propagation in the routing information. }\end{array}$ & There is no periodic updating \\
\hline $\begin{array}{l}\text { Traffic and the power utilization fright in general } \\
\text { in mobile and systems. }\end{array}$ & $\begin{array}{l}\text { There is no traffic and power consumption. } \\
\text { When compared to the on-demand protocols. }\end{array}$ \\
\hline $\begin{array}{l}\text { packet delivery latency is very less } \\
\text { when compared to the on-demand protocols . }\end{array}$ & $\begin{array}{l}\text { First packet delivery latency is more } \\
\text { when compare to the table driven protocols . }\end{array}$ \\
\hline There is a route to all other neighbour node. & That is not available in the reactive protocols . \\
\hline
\end{tabular}

\section{Simulation ANALYSIS AND PERformance MATRIC}

To investigate network performance, researchers can simply use an easy-to-use scripting language to configure a network, and observe results generated by NS2[13]. Undoubtedly, NS2 has become the most widely used open source network simulator, and one of the most widely used network simulators. It began as a part of the REAL network simulator and is evolving through an ongoing collaboration between the University of California at Berkeley and the VINT project [14].

\section{A. Performance Metric}

The following different performance metrics are evaluated to understand the behavior of DSDV and AODV routing protocols

- Normalized Routing Overhead.

- Throughput.

- Packet Delivery Ratio.

\section{B. NS2 Environment}

We have used Linux for NS2.The hardware specification of the Linux that we have used is an follows.

Processor:Intel(R)Core(TM)i3CPUM 370@2.40

Linux Kernel Version: Linux 2.6.18-53.el5 i686
Total Memory: $515524 \mathrm{~KB}$

The Simulation environment that we have used for our simulation are:

Table 2. Simulation Environment

\begin{tabular}{|l|l|}
\hline \multicolumn{1}{|c|}{ Parameter } & \multicolumn{1}{c|}{ Values } \\
\hline Simulator & NS2(Version 2.34) \\
\hline Channel Type & Channel/Wireless Channel \\
\hline Radio-propagation model & Propagation/TwoRayGround \\
\hline Network Interface Type & Phy/WirelessPhy \\
\hline MAC Type & Mac/802.11 \\
\hline Interface Queue Type & Queue/DropTail/ PriQueue \\
\hline Link Layer Type & LL \\
\hline Antenna Model & Antenna/OmniAntenna \\
\hline Maximum packet in ifq & 50 \\
\hline Area(M*M) & 800 \\
\hline Source Type & CBR \\
\hline Routing Protocol & DSDV and AODV \\
\hline
\end{tabular}




\section{NS2 Directory Structure}

The main directory of the NS2 simulation is nsallinone. There are subdirectories under the ns-allinone. The allinone denotes that all the directories or features used for running tcl file is included in the directory itself.
The subdirectory ns- 2 contains the $\mathrm{Tcl}$ and the $\mathrm{C}++$ code, the $\mathrm{C}++$ classes of ns- 2 network components or protocols are implemented in the subdirectory "ns-2", and the Tcl library in the subdirectory of "tcl".

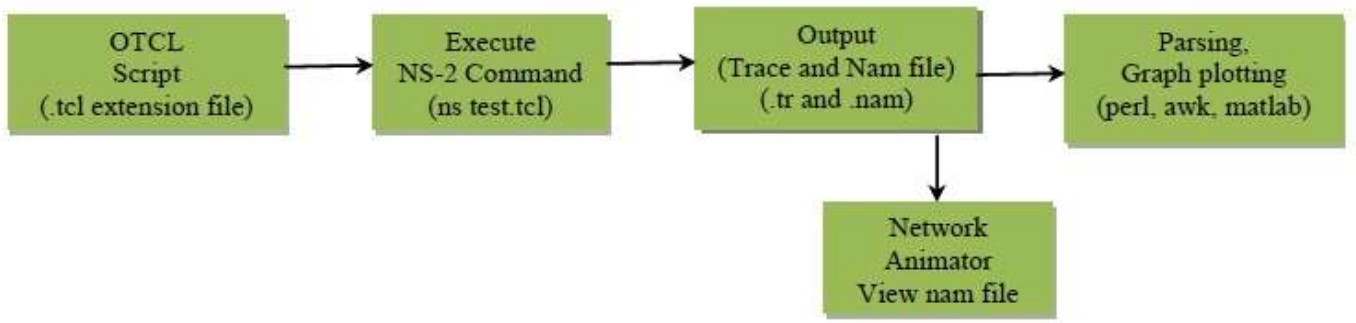

Fig. 7. Basic architecture of NS2

The $\mathrm{C}++$ acts as the backend of the simulator. All the routing Protocols I have used am written in the $\mathrm{C}++$. The main scripting for the Environment are done in Tcl. The $\mathrm{C}++$ and $\mathrm{Tcl}$ are joined using Tclcl.

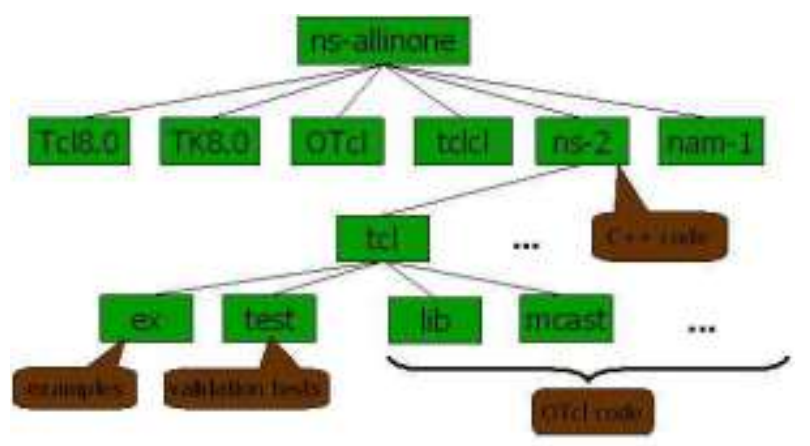

Fig. 8. NS2 Directory Structure

Figure 7 depicts the overall process of how a network simulation is conducted under NS-2. Output files such as trace files have to be parsed to extract useful information. The parsing can be done using the awk command (in UNIX and LINUX, it is necessary to use gwak for the windows environment) or perl script. The results have been analyzed using Excel . A software program which can shorten the process of parsing trace files (Xgraph and TraceGraph) has also been used in future work.

\section{Results}

Generated trace file that is (.tr)

s -t 2.000000000 -Hs 1 -Hd -2 -Ni 1 -Nx 282.78 -Ny

298.25 -Nz 0.00 -Ne 10.000000 -NI AGT -Nw - -Ma 0 -Md 0 -Ms 0 -Mt 0 -Is 1.0 -Id 3.0 -It cbr -Il 210 -If 0 -Ii

0 -Iv 32 -Pn cbr -Pi 0 -Pf 0 -Po 1 setdest Syntax:

We use another command to create run time environment for NS 2.

setdest -n val -M val -P val -t val -x val -y val

Setdest is a command used to create the runtime environment for NS2.

Where

- n: Numbers of nodes.
- M:speed(Mobility).

- P:pause time.

- t:similuation time.

- $\mathrm{x}$ : $\mathrm{x}$ coordinate.

- y:y coordinate.

\section{E. NAM file output}

NAM is a Tcl/TK based animation tool for viewing network simulation traces and real world packet traces. Taking data from network simulators (such as ns) or live networks, NAM was one of the first tools to provide general purpose, packet-level, and network animation, before starting to use NAM, a trace file needs to create [13]. This trace file is usually generated by NS. Once the trace file is generated,NAM can be used to animate it. A snapshot of the simulation topology in NAM for 15 mobile nodes is shown in figure 9, which is visualized the traces of communication or packets movements between mobile nodes [14].

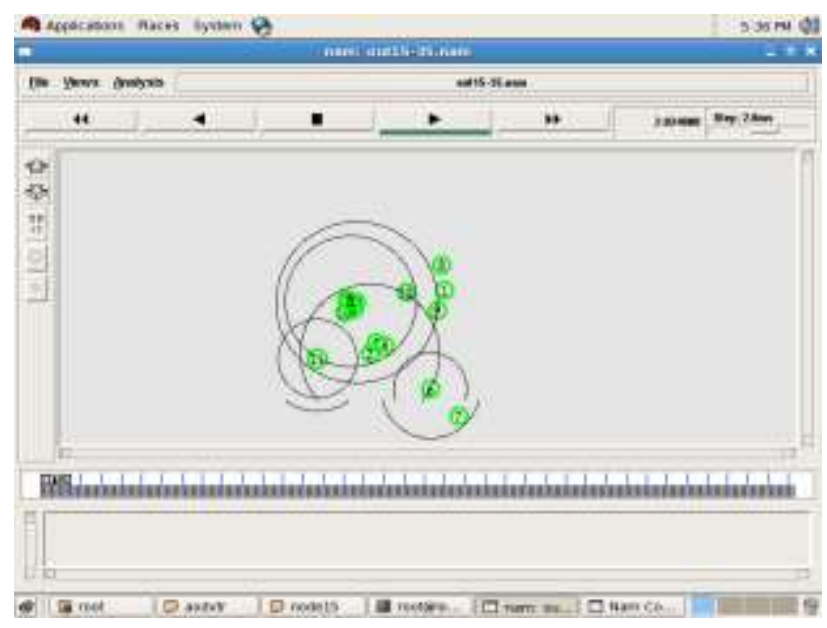

Fig. 9. A simple Nam output

\section{GRAPHICAL ANALYSIS}

\section{A. Packet Delivery Ratio(PDR)}

The ratio of the number of data packets successfully delivered to the destinations to those generated by CBR 
sources. The higher the delivery ratio, better is the performance of the routing protocol.

PDR is determined as:

Packet delivery Ratio $=($ Received packets $/$ Sent packets)*100

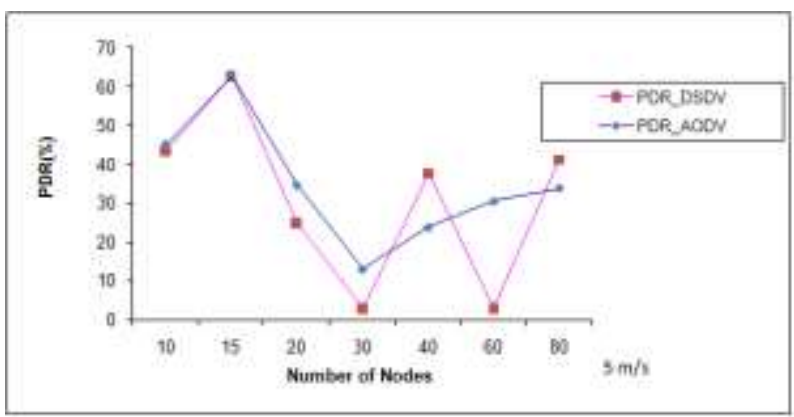

Fig. 9. Packet Delivery Ratio (PDR) at $5 \mathrm{~m} / \mathrm{s}$.

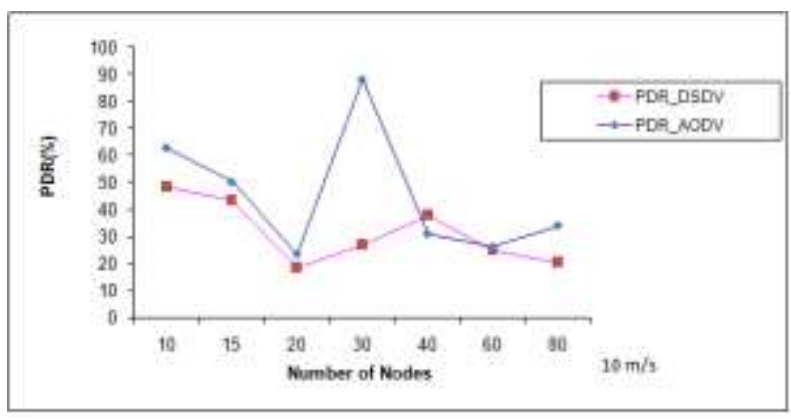

Fig. 10. Packet Delivery Ratio (PDR) at $10 \mathrm{~m} / \mathrm{s}$.

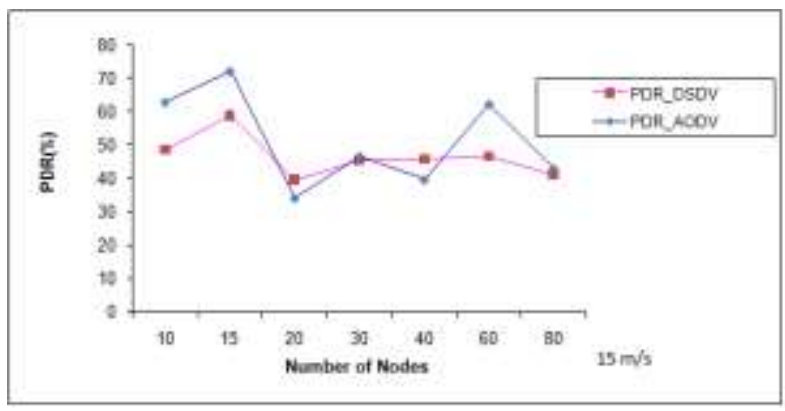

Fig. 11. Packet Delivery Ratio (PDR) at $10 \mathrm{~m} / \mathrm{s}$.

The Figure 9, Figure 10 and Figure 11 clearly indicate that the AODV routing protocol shows the better performance in most cases for PDR with the CBR traffic. However in the low node scenario i.e. 7 node scenario it perform better with the TCP traffic but with all other network scenarios the protocol outcomes better with the CBR traffic. AODV protocol performs better in comparison of other two selected routing protocols in such network environment. The performance of AODV is better from DSDV in low traffic but not significant or can say lesser from the outcome of AODV routing protocol performance with both CBR and TCP traffic.

\section{B. Throughput}

Throughput is defined as; the ratio of the total data reaches a receiver from the sender. The time it takes by the receiver to receive the last message is called as throughput. Throughput is expressed as bytes or bits per sec (byte/sec or bit/sec). Some factors affect the throughput as; if there are many topology changes in the network, unreliable communication between nodes, limited bandwidth available and limited energy .A high throughput is absolute choice in every network.

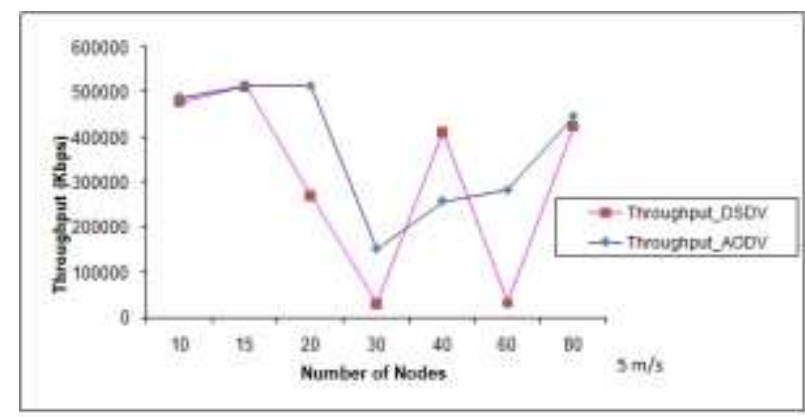

Fig. 12. Throughput at $5 \mathrm{~m} / \mathrm{s}$.

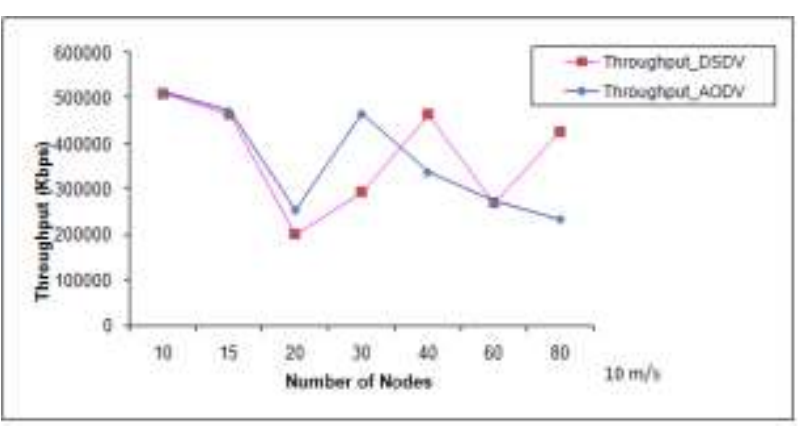

Fig. 13. Throughput at $10 \mathrm{~m} / \mathrm{s}$.

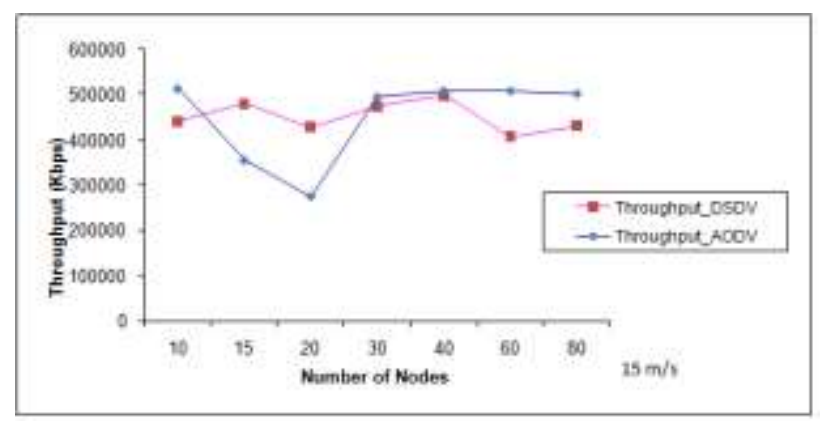

Fig. 14. Throughput at $10 \mathrm{~m} / \mathrm{s}$.

Based on the result of simulation as indicated in Figure 12, Figure 13 and Figure 14 shows that performance of AODV is better than DSDV. Another characteristic that has come to the notice is that pause time does not have significant bearing on the throughput whereas the performance is dictated only by the density of the network. After analyze the simulation work we say that AODV gives the better throughput.

\section{Normalized Routing Overhead}

It is the total number of control or routing (RTR) packets generated by routing protocol during the simulation. All packets sent or forwarded at network layer is consider routing overhead.

Routing Overhead $=$ Number of RTR packets 


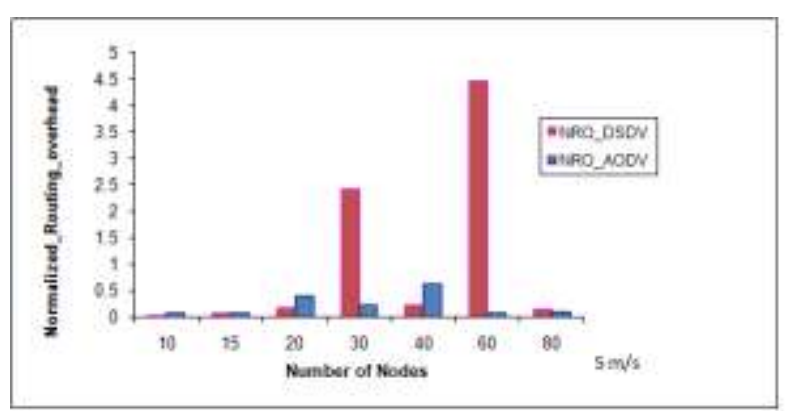

Fig. 15. Normalized Routing Overhead at $5 \mathrm{~m} / \mathrm{s}$.

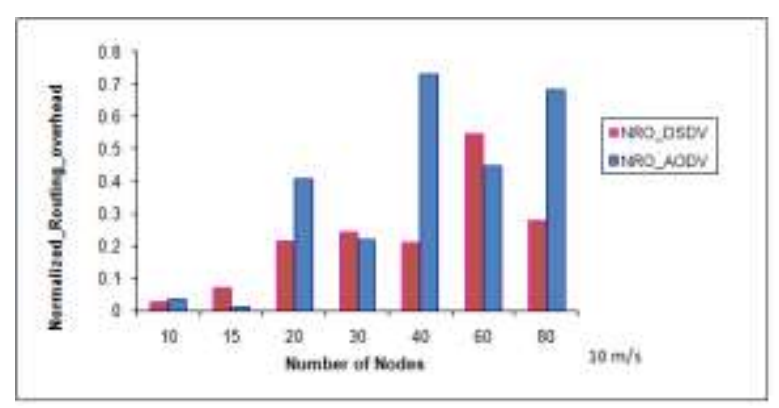

Fig. 16. Normalized Routing Overhead at $10 \mathrm{~m} / \mathrm{s}$.

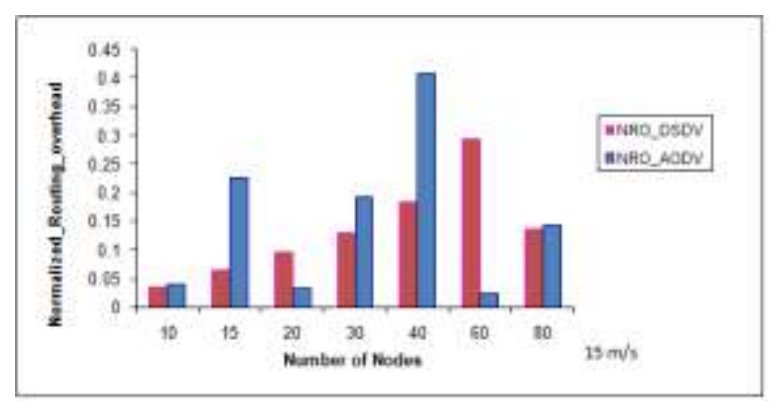

Fig. 17. Normalized Routing Overhead at $15 \mathrm{~m} / \mathrm{s}$.

Figure 15, Figure 16 and Figure 17 indicates that normalized routing overhead of AODV is always higher than DSDV under any scenario. The performance of DSDV in terms of normalized routing overhead is not influenced in any way with respect to change in node density and pause time. The reactive nature of AODV routing protocol causes more number of control overhead than DSDV. Therefore, normalized routing overhead for AODV will always be higher than DSDV.

\section{CONCLUSION}

The performance evaluation of two routing protocols, AODV and DSDV, has been done with respect to metrics viz. throughput, PDR and normalized routing overhead under varying node density and varying pause time. From the result analysis, it has been observed that in high node density the performance of both protocols decreases significantly. It has been observed that in low node density the performance of AODV is better than DSDV in terms of throughput, whereas the performance of DSDV is better in high node density (upto 80 nodes). In Current work, only three performance metrics have been considered to analyze the performance of AODV and DSDV. Inclusion of other performance metrics will provide in depth comparison of these two protocols which may provide an insight on the realistic behavior of the protocols under more challenging environment. Mobile Adhoc network is an upcoming area that is taking shapes slowly but steadily. During present work, impact of VBR traffic was also tried and studied for all three protocols using NS2 but it didn't worked out as NS2 does not support VBR traffic. It was observed that VBR traffic can be studied using another simulator GloMoSim which supports this type of traffic.

\section{ACKNOWLEDGMENT}

We thank anonymous referees for their suggestion to revise the paper. Subhrananda Goswami is grateful to Haldia Institute of Technology(HIT),Haldia,Purba Medinipur, West Bengal, India , for the environmental support to do this work.

\section{REFERENCES}

[1] Tanenbaum, S.A. (2002) 'Computer Networks' PRENTICE HALL.

[2] Nadia Qasim, Fatin Said, Hamid Aghvami ," Mobile Ad Hoc Networks Simulations Using Routing Protocols for Performance Comparisons", Proceedings of the World Congress on Engineering 2008 Vol I WCE 2008, July 2 - 4, 2008, London, U.K.

[3] C. E. Perkins, E. M. Royer, I. D. Chakeres, "Ad hoc OnDemand Distance Vector (AODV) Routing Protocol", draft-perkins-manet-aodvbis-00.txt, October 2003.

[4] Azzedine Boukerche "Algorithms and Protocols for Wireless, Mobile Ad Hoc Networks", 2008.

[5] Bulent Tavli "Mobile Ad Hoc Networks: Energy-Efficient Real-Time Data Communications", 2006.

[6] Mohammad llyas,Richard C. Dorf "The handbook of ad hoc wireless networks", 2003.

[7] Internet Engineering Task Force MANET Working Group Charter. http://www.ietf,org/html.charters/manetcharter.html.

[8] J. Broch, D. A. Maltz, D. B. Johnson, Y-C. Hu, and J.Jetcheva. "A Performance Comparison of Multi-hop Wireless Ad Hoc Networks." In Proceedings of the 4th Int. Conjkrence on Mobile Computing and Networking (ACM MOBICOM'98), pp. 85-97, October 1998.

[9] D. B. Johnson, D. A. Maltz, and J. Broch. "The Dynamic Source Routing Protocol for Mobile Ad Hoc Networks," lntemet Draft, MANET Working Group, draft-ietf-manetdsr-03.txt, November 1999.

[10] Perkins,C.E., Belding-Royer, E.M. and Das, S.R. (2003) 'Ad hoc On-Demand Distance Vector Routing', IEFT MANET Draft, Charles E. Perkins, Ad Hoc Networking, ISBN 0-201-3097.

[11] C. Perkins and E. Royer, "Ad Hoc On-Demand DistanceVector (AODV) Routing," Internet Draft, MANET Working Group, draft-ietf-manet-aodv-O5,txtM, $\operatorname{arch} 2000$.

[12] Ramesh, V., Subbaiah, P., Rao, N.K. and Raju, M.J. (2010) 'Performance comparison and analysis of DSDV and AODV for MANET', International Journal on Computer Science and Engineering, 02, 183-188. 
[13] Network simulator-ns-2. www.isi.edu/nsnam .

[14] NS Manual/Documentation-The VINT Project collaboration between researchers at UC Berkeley, LBL, USC/ISI and Xerox. PARC.KevinFall_kfall@ee.lbl.gov, Kennan Varadhan_kannan@catarina.usc.edu

[15] NS Manual/Documentation-The VINT Project Collaboration between researchers at UC Berkeley, LBL, USC/ISI and Xerox.PARC.KevinFall_kfall@ee.lbl.gov, Kennan Varadhan_kannan@catarina.usc.edu .

\section{Authors' Profiles}

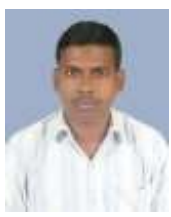

Mr. Subhrananda Goswami is an Research Scholar in Department of Computer Science and Engineering ,Haldia Institute of Technology, Haldia,West Bengal,India for the past 2 years. Currently, he is pursuing M.Tech in Computer Science and Engineering at Haldia Institute of Technology, Haldia. His research interests are: mobile adhoc networks, route optimization and other related topics.

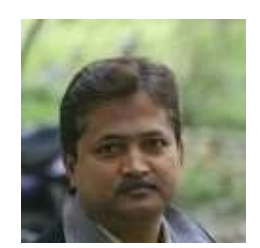

Mr. Subhankar Joardar is as an Assistant Professor in Department of Computer Science and Engineering, Haldia Institute of Technology,Haldia, India for the past 5 years. Currently, he is pursuing Ph.D. in Computer Science and Engineering at BIT, Mesra. He has published many papers in the International Journals (Refereed) and Conferences. His research interests are: Mobile adhoc networks, Swarm Intelligence, Advanced Algorithm design and other related topics.

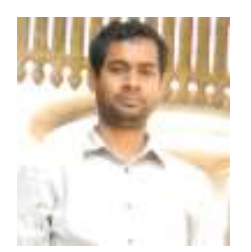

Dr. Chandan Bikash Das has a good research experience as he is involved in research for past 10 years. He is an Assistant Professor in Department of Mathematics, Tamralipta Mahavidyalaya,Tamluk, Purba Midnapur, West Bengal, India. He has published many research articles in the International \& National Conferences and Journals. His research interests are: Fuzzy System, Game Theory, Genetic Algorithm and other related topics.

Dr. Barun Das has a good research experience as he is involved in research for past 10 years. $\mathrm{He}$ is an Assistant Professor in Department of Mathematics, Sidho-Kanho-Birsa University, Purulia-723101, India. He has published many research articles in the International \& National Conferences and Journals. His research interests are: Fuzzy System, Inventory Theory, Genetic Algorithm, Solid Transportation Problem and other related topics.

How to cite this paper: Subhrananda Goswami, Subhankar Joardar, Chandan Bikash Das, Barun Das,"A Simulation Based Performance Comparison of AODV and DSDV Mobile Ad Hoc Networks", International Journal of Information Technology and Computer Science(IJITCS), vol.6, no.10, pp.11-18, 2014. DOI: $10.5815 /$ ijitcs.2014.10.02 